\title{
Artelogie
}

Recherche sur les arts, le patrimoine et la littérature de l'Amérique latine

8 | 2016

Transgression dans les arts / transgression des arts

\section{El Teatro Militante: subversiones y resistencias durante la dictadura cívico-militar uruguaya (1973-1985)}

Luciana Scaraffuni

\section{(2) OpenEdition}

Journals

Edición electrónica

URL: http://journals.openedition.org/artelogie/422

DOI: 10.4000/artelogie.422

ISSN: 2115-6395

Editor

Association ESCAL

Referencia electrónica

Luciana Scaraffuni, «El Teatro Militante: subversiones y resistencias durante la dictadura cívicomilitar uruguaya (1973-1985) », Artelogie [En línea], 8 | 2016, Publicado el 26 enero 2016, consultado el 10 diciembre 2020. URL : http://journals.openedition.org/artelogie/422 ; DOI : https://doi.org/

10.4000/artelogie.422

Este documento fue generado automáticamente el 10 diciembre 2020.

Association ESCAL 


\title{
El Teatro Militante: subversiones y resistencias durante la dictadura cívico-militar uruguaya (1973-1985)
}

\author{
Luciana Scaraffuni
}

\section{El escenario teatral montevideano}

1 En el siguiente artículo, así como también en la investigación realizada ${ }^{1}$, las agrupaciones teatrales independientes que analizo son: El Galpón, el Teatro Circular de Montevideo (TCM) y Teatro Uno. Con respecto al posicionamiento de estas agrupaciones como teatros independientes, las premisas que guiaban esa independencia fueron base de la creación de la Federación Uruguaya de Teatros Independientes (F.U.T.I) en 1947, que entendía por "independiente" : 1) independencia de toda sujeción comercial, de toda injerencia estatal limitativa ; 2) teatro de arte: lo cual refiere a una búsqueda por medio de la continua experimentación; 3) teatro Nacional: respecto a una actitud fermental sobre la colectividad ; 4) teatro popular : ya que se busca obtener la popularización del teatro; 5) organización democrática: en el sentido de un trabajo colectivo; 6) intercambio cultural ; 7) militancia: en el sentido de una activa participación con respecto a la situación del hombre en la comunidad (PIGNATARO, 1968).

Aunque el concepto de independientes iba de la mano de la concepción que estos teatreros tenían acerca de qué es la política, la militancia, la ideología, también de su sentir y ser de izquierda ; iba de la mano de sentires varios, de valores, de principios, de ideales y de sueños. Dado que los mismos teatreros son quienes construirán los teatros y generarán las infraestructuras necesarias, para poner en escena los repertorios que las agrupaciones consideren debían realizar.

3 Al hacer referencia al teatro independiente se debe señalar que esta experiencia comienza, en ambas orillas del Río de la Plata, es decir, con proyectos similares en las ciudades de Montevideo y Buenos Aires. En el año de 1937 en Montevideo, con la fundación del Teatro del Pueblo por Manuel Domínguez Santamaría, a partir del cual se 
escindiría la agrupación teatral El Galpón a la cual me refiero aquí. Mientras que en el año de 1930 en Buenos Aires, Leonidas Barletta ya había fundado un proyecto similar. Apropiándose de los preceptos del dramaturgo francés Romain Rolland quien afirma que el Teatro del Pueblo es la herramienta de expresión de una nueva sociedad, es en épocas de crisis una máquina de guerra contra la sociedad envejecida (ROLLAND, 1953)

Es decir, que el teatro independiente no solo involucra puestas en escena comprometidas con una realidad social uruguaya y/o latinoamericana, sino que involucra una experiencia colectiva de construir las salas, un proceso de trabajo comunitario y cooperativo donde el grupo es más fuerte que la suma de sus partes, y brinda un sentido de pertenencia, de identidad, de solidaridad y de integración a sus miembros.

\section{La politización del teatro y la represión en la antesala al golpe de Estado (1968-1973)}

Este primer período o bloque al cual haré referencia, se encuentra comprendido entre los años 1968 y 1973, el accionar teatral de los independientes tiene como finalidad generar una consciencia política y social en los individuos, que trasciende las opciones o tendencias estéticas utilizadas. En este primer bloque los teatreros optaban por obras que congregaran al espectador por el contenido político, más allá de las puestas en escena. Posicionan al teatro independiente como una herramienta que tiene una función social.

6 Los años que abarca este bloque se consideran como el período pre-golpe de Estado, marcado por la época convulsionada y efervescente de los años 60s, con Jorge Pacheco Areco en la presidencia (1967-1972), y la instauración de las Medidas Prontas de Seguridad a través de un estado de sitio interno y de la restricción de las libertades de los ciudadanos, medidas que buscaban asegurar el orden interno a través del control de la población. Sobre todo actuar contra la guerrilla política urbana que se había gestado, el MLN-Tupamaros (Movimiento de Liberación Nacional).

7 El año de 1968 el cual está marcado por la implantación de las Medidas Prontas de Seguridad, lo cual se hizo sentir a través de un gran despliegue militar en la ciudad, la agrupación teatral El Galpón estrena la obra Libertad, Libertad en su primer sala ubicada en las calles Mercedes y Carlos Roxlo. Es una pieza que tuvo varias fechas de realización : en 1968, en 1971 y en 1974 en el exterior, dado que para esa fecha ya había ocurrido el golpe de Estado y ya se había proscripto al Partido Comunista, por lo que la seguridad de la mayoría de los teatreros de El Galpón quienes se encontraban afiliados a este partido se vio comprometida.

8 Teatreros como Dardo 'el Rulo' Delgado, Stella Texeira, Miriam Gleijer son algunos integrantes de El Galpón que fueron parte de la puesta en escena de Libertad, Libertad. Obra bajo la dirección de César Campodónico, esposo de Stella Texeira, hoy difunto. César Campodónico fue uno de los fundadores de El Galpón, comenzó su formación artística en el Teatro del Pueblo con su creador Domínguez Santamaría ; fue profesor de geografía y antiguo militante del Partido Comunista; tuvo que exiliarse durante la dictadura militar uruguaya junto con Stella ${ }^{2}$, al igual que con varios miembros de la agrupación teatral, a México luego de la clausura del teatro por parte del régimen.

9 El libreto de la obra Libertad, Libertad es de autoría de los brasileros Millor Fernándes y Arturo Rangel, del Grupo Opiniao de San Pablo, grupo teatral de los años 60s, que realizó teatro de protesta y de resistencia ${ }^{3}$, bajo la dirección de Augusto Boal. 

estaban viviendo en el mundo en aquella época llevó a El Galpón, a buscar textos que reflejaran dicho proceso. Hechos como los de la guerra de Vietnam, la revolución cubana y el estado pre-revolucionario del resto del continente, son hechos que no pueden ser pasados por alto para una agrupación teatral, cuyo quehacer teatral es militante. Cabe destacar que el fuerte principal de esta obra no era la estética, sino la reunión que generaba, es decir, se transformaba en un "acto político" de protesta, donde lo que se decía y cantaba tenía un rol central. Las vestimentas eran sencillas, un grupo de cinco teatreros pertenecientes al elenco estable de El Galpón, en una especie de coro, cantaban e interpretaban los textos y canciones políticas sobre los cuales habían trabajado.

como Libertad, Libertad al igual que la clásica Fuenteovejuna del español Lope De Vega -también realizada por la institución El Galpón en el año 1969- tuvieron entre noventa y cien mil espectadores, y se mantuvieron cuatro temporadas en cartelera. La versión de Fuenteovejuna se realizó para el vigésimo cumpleaños del teatro y fue una adaptación libre a cargo de Antonio Larreta y Dervy Vilas. Antonio Larreta era otro hombre de teatro, perteneció a la agrupación teatral independiente disuelta en dictadura "Club de Teatro", mientras que el entrañable Dervy Vilas, es 'galponero' fundador de la agrupación.

Para esta puesta en escena ya es inminente la instauración y apropiación de los métodos brechtianos utilizados por las agrupaciones independientes, sobre todo por El Galpón, dado que Bertolt Brecht fue un dramaturgo fundamental en la configuración del quehacer teatral militante de la época. El crítico teatral Roger Mirza sitúa estas obras dentro de lo que él caracteriza como el sistema teatral de los años sesenta (2007), el cual se destaca por un teatro militante de alto compromiso social y político, donde los elementos que definen al teatro en su sentido más convencional se modifican. Es decir que "muchas veces no hay texto dramático, la creación es colectiva, las nociones de puesta en escena y de espacio escénico se alteran, las relaciones con el espacio de recepción se transforman, etc" (VERZERO, 2013 : 40). En este teatro militante hay fuertes elementos de índole social, político, ideológico que se buscan transmitir.

13 La adaptación de Fuenteovejuna por Larreta está radicada al contexto uruguayo y al resto de América Latina, donde se vivía una época de violencia estatal.

Bertolt Brecht pasa a ser el referente y guía en torno a los repertorios, los métodos y el paradigma teatral que se instala en este bloque. Esto a su vez se encuentra permeado por la militancia político-partidaria de los teatreros que si bien no es un requisito para pertenecer a ninguna agrupación teatral independiente, sobre todo los teatreros de El Galpón tenían su fuerte pertenencia al Partido Comunista Uruguayo.

15 Ya desde esta época se instala la persecución contra el campo cultural, se les hace un seguimiento a las obras y a los teatreros de las diferentes agrupaciones, ya que los teatros son visitados por diferentes oficiales que corresponden a la Dirección Nacional de Información e Inteligencia (D.N.I.I) del Estado uruguayo, donde la figura más recordada por los teatreros es el inspector Alén Castro, quien se encargaba de visitar las obras, realizar informes, leer los libretos para su autorización.

El clima que ya desde mediados de los sesentas se había comenzado a vivir, donde Uruguay así como el resto de América Latina, se tornaba un escenario más de la Guerra Fría, en el cual se aplicaba la Doctrina de Seguridad Nacional como en la mayoría de los países de la región. La ejecución de esa Doctrina tuvo sus especificidades en cada país. En Uruguay comenzó una pérdida de la prosperidad económica que el país había tenido a 
mediados de los años cincuenta y de la imagen que se había consolidado desde principios del siglo XX, como una sociedad con una legislación laboral de avanzada, unos derechos políticos extensivos a las mujeres y un Estado de Bienestar sólido.

En agosto de 1968 bajo el régimen de Medidas Prontas de Seguridad, la policía mata al primer estudiante Líber Arce, estudiante de odontología que se encontraba manifestando en las inmediaciones de la facultad de veterinaria.

18 La condena a las movilizaciones sociales era reflejo de la polarización política mundial, el discurso anti comunista en Uruguay, se venía instalando desde mediados de los cincuenta, esto provoca la estigmatización del movimiento social y estudiantil que era visto como el que respondía a los lineamientos e ideas del movimiento comunista internacional. Esto estaba asociado además al hecho de que el Partido Comunista Uruguayo, a lo largo de los años sesenta, tuvo una expansión sustancial de los espacios juveniles de militancia (MARKARIAN, $2010 ; 2012$ ).

19 En este contexto las obras teatrales que optaban por poner en escena los teatreros eran principalmente de denuncia de la realidad social que se estaba viviendo, donde además de las obras mencionadas y del peso que adquiere Bertolt Brecht. La incorporación de los métodos y técnicas de este dramaturgo, entraban en consonancia con los compromisos políticos y militantes que asumían los teatreros por esta época, lo cual a su vez está relacionado con su forma de funcionamiento y la organización de cada agrupación.

El teatro El Galpón y el Teatro Circular de Montevideo, tenían un funcionamiento similar, las decisiones se tomaban en asambleas, esta era la vía para la elección del repertorio. Esta forma de proceder se encuentra emparentada de cierta forma con la militancia político-partidaria que tenían la mayoría de sus miembros y que los socializó a actuar en bloque. Esto debido a que quienes integraban la comisión directiva de El Galpón pertenecían al Partido Comunista, mientras que varios miembros del Teatro Circular de Montevideo fundaron la sección cultural del 26 de Marzo, sector de izquierda perteneciente al Frente Amplio, fuerza política que aglomera todos los partidos y sectores de la izquierda uruguaya fundada en 1971.

21 Teatro Uno sin embargo, no tenía las mismas características que las dos agrupaciones anteriores y si bien uno de sus fundadores Alberto Restuccia, fue miembro del Partido Comunista desde muy joven, debido a su trabajo como obrero portuario, dentro del campo teatral y entre los propios teatreros de izquierda presentaba divergencias fuertes por elecciones estéticas, de puestas en escena y artísticas.

Estas agrupaciones se apropiaron de Brecht de maneras distintas, el Teatro Circular realizó en el año 1972 Los Fusiles de la patria vieja, versión libre de Los Fusiles de la Madre Carrar de Bertolt Brecht dirigida por Omar Grasso el 28 de octubre de 1971, con un elenco de teatreros de distintos teatros independientes, eran dos elencos, uno que se desempeñaba en la puesta en escena realizada en la sala ubicada en el centro de Montevideo y otro elenco que recorría los barrios y se desempeñaba en los comités de base de la agrupación de izquierda Frente Amplio.

23 La adaptación que se realiza de esta obra es 'a la uruguaya', en el sentido de que el director Omar Grasso, localiza la acción que transcurre durante la Guerra Civil española a la provincia Cisplatina ((Des) archivo Brecht, 2015) Dado que según el programa de mano, la obra narra el desembarco de los Treinta y Tres orientales el 19 de abril de 1825 en la playa de la Agraciada, en el Departamento de Soriano y la declaración de la Independencia por parte de los representantes de los pueblos, quienes constituyeron el 
Gobierno patrio de la Provincia Oriental (hoy Uruguay) : 'Como en los tiempos de Artigas, las milicias revolucionarias luchan por la liberación popular, enfrentando al régimen impuesto por la oligarquía terrateniente y mercantil -los 'patricios' de Montevideoapoyada por el extranjero. ${ }^{4}$

La obra tuvo un gran impacto en lo que podría haber sido el futuro del Teatro Circular ad portas del régimen dictatorial, con la presencia del inspector policial Alen Castro rondando por los espectáculos y los teatros, con el fin de censurar, citar a declarar y encarcelar a los teatreros.

25 En este primer periodo de 1969 a 1973 algunas obras que le hicieron frente al autoritarismo y que de cierta forma fueron una molestia al régimen que cada día se consolidaba, se encuentran : La Reja de Andrés Castillo, Operación Masacre en base a la novela de Rodolfo Walsh, La Gotera de Jacobo Langser o Barranca abajo del autor nacional Florencio Sánchez dirigida por Atahualpa del Cioppo. Es menester destacar que en este período la influencia de Brecht es central. El 'paradigma Brechtiano', como indica Mirza, fue una herramienta primordial, ya que tanto El Galpón como el Teatro Circular, realizaron alrededor de ocho obras brechtianas (MIRZA, 2007; RAMIS, 2002). Entre el Círculo de Tiza Caucasiano, El Señor Puntila y su criado Matti, La ópera de dos centavos, La Madre, Los Fusiles de la patria Vieja adaptación de Los Fusiles de la Madre Carrar, La Resistible Ascensión de Arturo Ui y Los Días de la Comuna de París tenemos un conjunto significativo de obras de Brecht adaptadas por los independientes.

26 La importancia de este dramaturgo alemán se sitúa en el rol que le concede al teatrero y a las funciones que este debe desempeñar: no solo entretener, sino concientizar al individuo. El modelo brechtiano del teatro épico, consistente en dejar los espectáculos con una estructura abierta, es decir, no proponer soluciones, sino generar distanciamiento y extrañamiento, busca hacer que el individuo reflexione crítica y objetivamente acerca de la realidad en la que vive ( CUADERNOS DE ARTE DRAMÁTICO, 1959). El teatro no solo es arte, sino que el teatro independiente se vuelve un proceso experimental con una funcionalidad socio-política, en la que se confronta el propio ámbito, la realidad, la memoria colectiva e individual ; las preocupaciones estéticas pasan por las decisiones políticas e ideológicas de los montajes (MIRZA, 2007 ; VERZERO, 2013)

27 En el año de 1972 se realiza una puesta en escena que terminará siendo problemática para la agrupación ad portas de la consolidación del régimen dictatorial en junio de 1973 y las gestiones emprendidas por el régimen para clausurar el teatro en 1976. La obra que se realiza es La Reja, de Andrés Castillo, podríamos decir que está basada en un 'teatro documento', es decir, a partir de la investigación de documentos encontrados en el parlamento uruguayo, se construyó una obra que aborda hechos que deberían ser históricos ya para esta época. Esta pieza fue una puesta en escena de creación colectiva entre Andrés Castillo y los teatreros de El Galpón que, si bien siguiendo la idea de ser una obra de imaginación y de elaboración simbólica frente a hechos históricos, generó una molestia en el régimen debido a los hechos que abordaba. Esta obra fue estrenada el 11 de agosto de 1972, en la sala de la calle Mercedes de El Galpón. Cuando los militares allanaron el teatro en el año de 1976, incautaron el libreto de la obra, que trata acerca de mujeres presas en el centro de reclusión en la ex Escuela de Nurses Dr. Carlos Nery, ubicada en el casco antiguo, el barrio Ciudad Vieja de Montevideo. Los hechos de esta obra ocurrieron en Uruguay en el año de 1968 y fueron registrados en documentos oficiales del parlamento uruguayo ${ }^{5}$. El centro de reclusión que se ponía en escena en la 
pieza, estaba ubicado en el casco antiguo de la capital, donde se encontraban ministerios, oficinas estatales, bancos, museos, galerías de arte, entre otros establecimientos.

La puesta en escena de la obra invoca un 'Local de reclusión para mujeres. No es una cárcel sino un lugar de confinamiento. Habrá varias cuchetas de dos camastros, un escritorio, sillas y algún otro adminiculo. Todo da sensación de amontonamiento. Al levantarse el telón está iluminada una sola cama, en la que habrá una presa dormida, vigilada por una policía que escribe. Las demás presas también duermen, pero no se advierten claramente en la oscuridad general. Al final del monólogo crecerá la luz y será de mañana'. ${ }^{6}$

Esta obra implicará para el año 1973 que los teatreros sean citados a declarar a la Dirección Nacional de Información e Inteligencia, ya que la mayoría fueron citados al departamento 6 a declarar acerca de su filiación al Partido Comunista y por algunos espectáculos realizados. También citaron al propio Andrés Castillo, quien fue cuestionado en torno a su colaboración en la construcción de esta pieza.

En este período la escenificación de lo que se quería decir o denunciar en torno a la realidad socio-política que se vivía era posible, aunque los inspectores y policías realizaban visitas periódicas a los teatros y documentaban mediante informes $\mathrm{u}$ oficios lo que sucedía en las obras que se decidían poner en escena. Esto va a tener un efecto en el corto plazo, dado que luego de la vigilancia de las obras, obras como La Reja y Libertad, Libertad son las que aparecerán identificadas en el decreto de clausura que emitirá el régimen en el año 1976 contra el teatro El Galpón.

\section{Las subjetividades en resistencia : cuando se pone en escena lo que no se puede decir durante la dictadura cívico-militar (1973-1985)}

31 Durante el período de perpetración del golpe de estado encabezado por Juan María Bordaberry, los artistas del campo teatral independiente debieron moverse, tal como lo señalara el director teatral Rubén Yáñez, en tres niveles que se interrelacionaban: la cárcel, el exilio y el ámbito público. El golpe de estado se puede caracterizar como un golpe cívico-militar, debido a que estuvo ejecutado y organizado tanto por civiles que pertenecían a distintos ámbitos de la sociedad civil (políticos, eclesiásticos y médicos entre otros), como por militares. Entre las características de este régimen se encuentra el haber sido un 'régimen internamente impuesto', como lo señala Álvaro Rico, dado que fue impuesto y ejecutado por el propio presidente electo, quien devino así en dictador, por medio de una usurpación del poder, destacándose que no hay una continuidad en la legitimidad de los principios que invisten al cargo (2009). A esto se debe agregar que el golpe se ejecuta en pos de centralizar y concentrar el poder, de lograr que no se produzcan desafíos en torno al monopolio de la fuerza de las armas, ni que se generen oposiciones político-partidarias, ni resistencias sociales u obreras. Hubo una participación corporativa de las Fuerzas Armadas, que en los momentos de mayor represión, tuvieron un papel fundamental en el intervencionismo directo en la actividad políticagubernamental (RICO, 2009).

Se torna importante destacar que el terrorismo de Estado desarrolló ciertas teatralidades en los espacios públicos urbanos mediante despliegues que instauraron una 'cultura del miedo' (PERELLI \& RIAL, 1986). Entre estos procesos estaba la reafirmación de la presencia 
del régimen mediante la militarización de las calles a través de tanques de guerra o de desfiles militares, por ejemplo. En este sentido, el terrorismo de Estado despliega toda una performatividad en pos de coersionar a la audiencia y paralizarla mediante el abuso y la presencia de la fuerza (TAYLOR, 1990). Como plantea Diana Taylor, el terrorismo de Estado actuó mediante una 'propensión teatral' que buscaba generar una división en la sociedad, en pos de excluir la socialización y la movilización ; todos eran vulnerables y el ataque podía surgir en cualquier momento y desde cualquier lugar (TAYLOR, 1990). A través de este posicionamiento en las calles, el régimen desestabilizó la sociedad mediante actos de violencia simbólica, y junto con el despliegue sistemático de violencia, persecuciones y torturas contra la población, de la cual se buscó la adhesión a un 'consenso cultural' que se apoyó en tácticas de terrorismo de Estado tales como detenciones arbitrarias y desapariciones forzadas (MARCHESI, 2009)

En este contexto se produce un quiebre en la vida de los teatreros, tanto en su quehacer teatral, como en sus cotidianeidades. Para muchos esta situación marcó el paso a la clandestinidad tanto en ámbitos de militancia político-partidaria, así como también dentro del campo cultural, dado que debieron replegar su accionar y su visibilidad para poder sobrevivir. Para otros marcó la experiencia traumática de la tortura, el encarcelamiento y posteriormente la libertad vigilada ; finalmente, para otros, significó el exilio a México, Buenos Aires o Europa y su contracara, el inxilio.

Esta situación produce un repliegue al ámbito de 'lo privado', es decir, a la familia y a los núcleos más íntimos de amigos y familiares. Lo que era público, como por ejemplo, la política, se tornó privada; solamente en el ámbito familiar se podían mantener conversaciones de esa índole. El campo cultural se vio afectado debido a que la dictadura concibió al campo cultural independiente como su 'antónimo', como una amenaza, por ende, arremetió contra su configuración. Pero lejos de lograr un 'apagón cultural', provocó que éste estuviera en constante re-organización y re-significación, planteándose estrategias de resistencia, tanto para el teatro independiente, como para: el canto popular, la escena del Rock, el campo del cine y del audiovisual y del arte en general (EL GALPÓN, 1983 ; MARCHESI, 2009 ; DE ALENCAR PINTO, 2013)

Dentro de las preocupaciones de este período se encuentra la de generar una dramaturgia nacional, debido a la imposibilidad de poder expresar y a la necesidad de poner en escena la realidad que se vivía. Por esto es que tanto para el teatro El Galpón, como el Teatro Circular y otros teatros independientes, los talleres de creación y los seminarios de dramaturgia eran importantes, ya que de ahí surgían piezas que tuvieron un papel central en la producción artística y en el mensaje que transmitían; se esperaba generar una postura crítica de la sociedad uruguaya, particularmente de la sociedad montevideana, frente a la condición histórica que le tocaba vivir. Un ejemplo de esto fue la pieza El Mono y Su Sombra, de la autora nacional Yahro Sosa, que se presentó a fines del año 1978 y, luego en la temporada del año 1979 en el Teatro Circular. Esta pieza era alegórica ; en el programa de mano de esta obra ${ }^{7}$ se indica que en ella se mantiene un lenguaje sugestivo para representar lo que sucedía con la represión en los años más duros de la dictadura.

Los teatreros concebían el quehacer teatral que llevaban a cabo como un arte popular, como algo construido y creado con el pueblo, como una actividad más de su cotidianeidad, un teatro que buscaba oponerse al teatro burgués, pero no de manera panfletaria o reaccionaria, sino de una forma que se enraizara en el pueblo, en la clase obrera, con la cultura popular (FOS, 2013). La elección del repertorio era una herramienta 
fundamental para el objetivo de mantener un teatro con nivel artístico y estético, además de político, dado que este siempre fue el objetivo de El Galpón hacer teatro de arte.

El teatro se volvió el ámbito de militancia por excelencia luego de que el régimen ilegalizara los partidos políticos uruguayos, entre ellos al Partido Comunista, este pasó a operar de forma clandestina ; mientras que para los teatreros comunistas significó militar contra la censura y el régimen establecido desde el campo cultural independiente, como también lo plantea Lorena Verzero para el caso Argentino (VERZERO, 2012)

Los grupos de teatro militante e independiente de Uruguay tendían puentes con la latinoamericanidad en pos de configurar un movimiento teatral latinoamericano, pero también respetaban las especificidades nacionales y los contextos históricos que se vivían en aquella época (VERZERO, 2012). En el proceso de elección del repertorio, se tenía en cuenta a los autores nacionales con la finalidad de poner en escena piezas que representaran historias uruguayas, como sucede con Florencio Sánchez. A su vez, esto tenía una significación especial debido a que dichas piezas mostraban una marcada postura antiimperialista, lo cual estaba relacionada con la propia formación política de los comunistas.

En este sentido es menester destacar la obra Doña Ramona, escrita por Víctor Manuel Leites y realizada en el teatro El Galpón en el año 1974 bajo la dirección de Amanecer Dotta. Dicha obra también fue puesta en escena en el Teatro Circular de Montevideo en el año 1982 bajo la dirección de Jorge Curi. Doña Ramona es una pieza inspirada en la novela de José Pedro Bellán, quien fuera un exponente de la 'Generación del 900'. Esta generación estuvo compuesta por varios escritores uruguayos cuyas obras literarias se enmarcarían en lo que sería el modernismo. Entre ellos se encontraban Horacio Quiroga, José Enrique Rodó, Florencio Sánchez, Julio Herrera y Reisig, María Eugenia Vaz Ferreria, entre otros.

La pieza Doña Ramona pone en escena el peso simbólico de la familia, es decir, la dictadura había tomado en su discurso a la familia como una de las instituciones centrales, pasó a ser una metáfora utilizada por el régimen, debido a que era la entidad que reunía lo público y lo privado en sí misma, la dictadura mediante su discurso buscó volver a 'lo esencial', preservar los valores de la nación del ataque subversivo y esto para el teatro fue clave (WERTH, 2010)

En el año 1976 citaron a los galponeros a declarar por segunda vez al edificio de la Dirección Nacional de Información e Inteligencia, luego de la clausura del teatro, la cual se ejecutó el 6 de mayo de 1976 apelando al decreto emitido por el Ministerio del Interior, el Ministerio de Defensa y el Ministerio de Educación y Cultura. Así como los partidos políticos y las organizaciones gremiales fueron proscritas, en el campo cultural, El Galpón también lo fue. Este decreto muestra los objetivos del estado en cuanto a las políticas culturales de su proyecto re-fundacional de la patria y sus apuestas culturales relacionadas con 'lo nacional'. No había cabida para El Galpón en este proyecto, dado que no solo clausuran el teatro, sino que además expropian la sala de la Avenida 18 de julio, que pasa a ser propiedad del régimen que la utiliza para actividades educativas y culturales.

Si bien el régimen controlaba todos los aspectos cotidianos, también se enfrentaba a ciertos 'bloqueos' en las prácticas cotidianas, es decir, eran pulseadas que se le realizaban al régimen en sus intentos por que los ciudadanos se adhirieran al consenso cultural y político que se quería imponer. (KERSHAW \& SIERRA, 2004 ; ORTNER, 2006) 

represivo, en este caso un régimen dictatorial, tienen agencia y pueden encontrar las formas de evadir y resistir, lo cual genera una dialéctica del control (ORTNER, 2006) cierta manera descuidados por este. Lo cual genera que la hegemonía impuesta por la dictadura nunca sea total en el sentido psicológico ya que la gente tiene cierto grado de penetración en las condiciones de su dominación.

Debemos entender que los teatreros pensaron y configuraron el campo cultural de forma vanguardista, en el sentido de que ellos también hicieron propias las discusiones que se generaban en el seno del partido acerca de la postura del comunismo internacional, en torno a las vías de la revolución, es decir, si la revolución es a través de la lucha armada o no, esto los posicionó en la construcción del propio campo cultural, entendiendo que la vanguardia no pasa por la guerrilla.

En esa construcción del quehacer teatral buscaron que las capas medias se acercaran a la clase obrera, ya que el arte debía servir para movilizar, para esto las obras debían comunicar eficazmente, comunicar que no es lo mismo que convencer. Brecht como estrategia era importante para el tratamiento de la realidad y su exposición, para darle herramientas a los individuos para que analicen la realidad y la puedan cambiar con sus 
propias acciones. Bertolt Brecht fue un dramaturgo que caló hondo en las estrategias y métodos teatrales que configuraron el quehacer teatral de los independientes, sobre todo en el cometido de unir a la clase media en la lucha obrera, hacerle comprender a los individuos sin embanderarse, ni fanatizarse, sino mediante la adopción de elementos críticos de la realidad, las desigualdades e injusticias sociales que estaba viviendo la sociedad uruguaya y latinoamericana en ese momento. Aunque a medida que la profesionalización del teatro independiente es mayor, se vio la necesidad de la construcción de una dramaturgia nacional, siempre con el objetivo de la construcción de un teatro nacional y popular, escrito por uruguayos para uruguayos, en este sentido los seminarios de dramaturgia tanto del Teatro Circular de Montevideo y de El Galpón contribuirán en esta línea.

En este sentido los teatreros pretendían dar cuenta de lo que estaba ocurriendo en el país, exponer las relaciones de poder que se estaban configurando, a través de una 'red' que según Richard Schechner, se tejía en diálogo entre lo que sucedía afuera con la instauración del autoritarismo y lo que se ponía en escena en las salas de los teatros independientes. Hay una evidente transgresión de las fronteras de un lado a otro, una porosidad que permite que dialogue 'lo micro', los montajes, la estética, las posturas ideológicas de los teatreros, con 'lo macro' materializado en el orden socio-político autoritario que vivía el Uruguay.

51 Se busca dar un sentido al drama social en el escenario teatral colectivamente, esto porque lo que se pone en escena son las reflexividades, tanto de los teatreros como de los individuos que asisten a la obra teatral, se representan narrativas reflexivas relacionadas con las experiencias (TURNER, 1982).

52 Por lo que nos lleva a pensar que los hechos y acontecimientos están configurados o moldeados por un quehacer teatral que va en contra de las estructuras establecidas por el régimen.

53 Es importante destacar que en esta relación dialéctica con el régimen, el teatro independiente se encarga de rescatar y re-configurar lo que para ellos hacía referencia a 'lo nacional', a 'lo uruguayo'. En este sentido, buscaron reunir al público que se encontraba fragmentado a través de metáforas e historias comunes, ya que el régimen buscó aislarlos.

La resistencia atraviesa los modos de convocatoria y de difusión de las obras, los repertorios seleccionados, los montajes, los usos y transformaciones espaciales tanto en las salas teatrales como por fuera de ellas, y las configuraciones ideológicas que adoptaba el quehacer teatral.

Las estrategias y astucias del teatro independiente para sobrevivir a la época estudiada, indican que los teatreros aprovechaban los intersticios del poder y se replegaban y expandían su accionar en torno a la agudización de la censura y represión. Las posturas y prácticas por las cuales optaban buscaban mantener ese espacio de socialización frente al proyecto del régimen de 'borrar' y terminar con espacios alternativos, que no respondían a los objetivos de la dictadura. 


\section{BIBLIOGRAFÍA}

ARRECHE Araceli (Comp.), Teatro obrero, una mirada militante sobre textos de Carlos Fos, Buenos Aires, Editorial Atuel, 2013.

BRECHT Bertolt, Breviario de Estética Teatral, Buenos Aires, Ediciones La Rosa Blindada, 1963 [1957]. BRECHT Bertolt, .Pequeño Organón para Teatro, 1948.

BRECHT Bertolt, La Ópera de Dos Centavos. Traducción: Annie Reney y Onofre Lovero, Buenos Aires, Ediciones Losange, 1957.

CAETAN Gerardo y RILla José, Breve Historia de la Dictadura, Montevideo, Ediciones de la Banda Oriental, 2005.

CAMPODÓNICo Cesar, El vestuario se apolilló. Una historia del teatro El Galpón, Montevideo, Ediciones Banda Oriental. 1999.

COMARoff Jean y COMARoff John 1991 of Revelation and Revolution. Christianity, Colonialism and Consciousness in South Africa. Volume One. The University of Chicago Press.

CORRADI Juan E., WEISS Fagen Patricia and GARRETON Manuel Antonio (editores), Fear at the edge: state terror and resistance in Latin America, Berkeley, University of California Press, 1992.

COSSE Isabela y MARKARIAN Vania,

1975: AÑO DE LA ORIENTALIDAD: Identidad, memoria e historia en una dictadura, Montevideo, Ediciones Trilce, 1996.

Cuadernos de Arte Dramático, Suplementos de Estudio: Documentación. Investigación. BERTOLT Brecht: para un teatro épico, Centro de Estudios de Arte Dramático, Buenos Aires, Editorial Raigal, 1953.

DEMASI Carlos, MARCHESI Aldo, et al., La dictadura Cívico-Militar: Uruguay 1973-1985, Montevideo, EBO, 2009.

El Galpón, “El Galpón”: Un teatro independiente uruguayo y su función en el exilio, Edición de las 2000 funciones en el exilio, Octubre de 1983, 1983.

escobar Arturo, S. ALVAREZ y E. DAgnino eds., Cultures of Politics- Politics of Culture, Westview Press, 1998.

GABAY Marcos, Política, Información y Sociedad. Represión en el Uruguay, contra la libertad de información, de expresión y crítica, Montevideo, Centro Uruguay Independiente, 1988.

GLEDHILL John, El poder y sus disfraces, Ediciones Bellaterra, 2000.

GONZÁLEZ Luis Eduardo, Estructuras Políticas y Democracia en el Uruguay, Montevideo, Fcu, 1993.

JELIN Elizabeth y LONGONI Ana (Comps.), Escrituras, imágenes y escenarios ante la represión, Madrid, Siglo Veintiuno editores, 2005.

MARCHESI Aldo, MARKARIAN, Vania, et. al., El presente de la Dictadura. Estudios y reflexiones a 30 años del golpe de Estado en Uruguay, Montevideo, Ediciones Trilce, 2004.

MARCHESI Aldo, El Uruguay inventado. La política audiovisual de la dictadura, reflexiones sobre su imaginario, Montevideo, Ediciones Trilce, 2001. 
MARCHESI Aldo, “¿Guerra o “terrorismo de Estado”? Recuerdos enfrentados sobre el pasado reciente uruguayo.", en Las conmemoraciones: las disputas en las fechas "in-felices", Argentina, México, Elizabeth JELIN (comp.), siglo XXI editores, $2001 \mathrm{~b}$.

MARKARIAN Vania y MARCHESI Aldo, Cinco décadas de estudios sobre la crisis, la democracia y el autoritarismo en Uruguay. Revista Contemporánea, Volumen 3, 2012, pp.213-241.

MARKARIAN Vania, Sobre Viejas y nuevas izquierdas. Los jóvenes comunistas uruguayos y el movimiento estudiantil de 1968, Secuencia, Revista de Historia y Ciencias Sociales, n81, 2011

MARKARIAN Vania, El 68 uruguayo: el movimiento estudiantil entre molotovs y música beat, Bernal, Universidad Nacional de Quilmes, 2012.

MIRZA Roger, La Escena Bajo Vigilancia: Teatro, Dictadura y Resistencia. Un microsistema teatral emergente bajo la dictadura en el Uruguay, Montevideo, Ediciones de la Banda Oriental, 2007.

MIRZA Roger (ed.), Teatro, memoria, identidad. Universidad de la República, Montevideo, Facultad de Humanidades y Ciencias de la Educación. Departamento de Teoría y Metodología Literarias. Ministerio de Educación y Cultura, 2009.

MIRZA Roger (ed.), El teatro de los sesentas en América Latina. Un diálogo con la contemporaneidad, Universidad de la República, Facultad de Humanidades y Ciencias de la Educación. Comisión Sectorial de Investigaciones Científicas, 2011.

MIRZA Roger y REMEDI, Gustavo (editores), La dictadura contra las tablas: teatro uruguayo e historia reciente, Montevideo, FHCE, 2009.

MORAÑA Mabel, Memorias de la generación fantasma, Montevideo, Editorial Monte Sexto, 1998.

ORTNER Sherry, Anthropology and Social Theory. Culture, Power and the acting subject, Duke University Press, 2006.

PERELLI Carina y RIAL Juan, De Mitos y Memorias Políticas. La represión, el miedo y después..., Montevideo, Ediciones Banda Oriental, 1986.

PIGNATARO CALERo Jorge, La aventura del teatro independiente uruguayo, Montevideo, Ed. Cal y Canto, 1997.

POoLE Deborah ed., Anthropology in the Margins of the State, SAR Press, 2004.

PUGA Ana Elena, Memory, Allegory, and Testimony in South American Theater. Upstaging Dictatorship. Routledge, New York. Versión online, 2008.

scotT James, Dominations and the Arts of Resistance. Hidden Transcripts, Yale, University Press, 1990. SCHECHNER Richard, The Future of Ritual, Taylor and Francis, 1995.

SCHECHNER Richard, Theatre and Anthropology, University of Pensilvania Press, 2001.

SOSNOWSKI Raúl (compilador), Represión, exilio y democracia: La cultura uruguaya, Universidad de Maryland, Montevideo, Ediciones de la Banda Oriental, 1987.

TURNER Victor, Anthropology of Performance, PAJ, 1988.

soSNOWSKI Raúl, Liminal to Liminoid, in Play, Flow, and Ritual: An Essay in Comparative Symbology, Rice University Studies, vol. 60, No. 3, Summer 1974 (Houston, Tex: Rice University), 1974, pp. 53-92 SOSNOWSKI Raúl, Frame, Flow and Reflection: Ritual and Drama as Public Liminality, Japanese Journal of Religious Studies, vol. 6, No. 4 (Dec., 1979), 1979, pp. 465-49 sosNOWSKI Raúl, From Ritual To Theater, 2001. 


\section{NOTAS}

1. El análisis parcial que se desprende en este artículo pertenece a la investigación doctoral para optar por el título de doctora en Antropología socio-cultural, titulada : "Las formas de resistencia durante la dictadura cívico-militar uruguaya (1973- 1985) : un estudio antropológico del teatro independiente", la cual se llevó a cabo desde el año 2011 hasta el año 2015 inclusive. En esta se analizan las representaciones, astucias, prácticas teatrales y el accionar político de los teatreros independientes uruguayos durante la dictadura cívico-militar (1973-1985), así como las transformaciones y efectos que dicha experiencia produjo en el quehacer teatral y en la esfera cultural más amplia antes y durante la dictadura. Esto se realiza mediante el examen de dos bloques o contextos históricos divisados, que tienen sus efectos en el quehacer teatral que los teatreros independientes configuran. El primer bloque abarca desde el año 1968 hasta el año 1973. Aquí se entiende que la constitución de la violencia política comienza antes del período dictatorial y que se sedimenta en ese período, pero que ya, desde el año 1968, se comenzaba a vivir un estado de excepción en Uruguay, bajo el despliegue militar del gobierno de Jorge Pacheco Areco (1967- 1972). El segundo bloque abarca los años 1973 a 1985, y tiene que ver con el régimen propiamente establecido, el cual instaura Juan María Bordaberry con la disolución de las cámaras parlamentarias el 27 de junio de 1973.

A partir de los dos bloques planteados, se analiza no sólo la producción de un quehacer teatral independiente que responde y está entretejido en las etapas históricas mencionadas, sino también como éste dialoga con las cotidianeidades, con las experiencias y con los 'mundos de vida' de los teatreros que también se deben adaptar a dichos contextos o bloques. Es decir, hay un relacionamiento dialéctico entre 'lo micro' (el día a día de los teatreros) y 'lo macro' (el régimen dictatorial) que permite analizar el efecto que la instauración gradual de la violencia estatal tuvo no sólo en el campo cultural sino en la cotidianeidad de los uruguayos, y en este caso específico de los teatreros independientes. Esto va a determinar que el movimiento teatral independiente, más específicamente las tres agrupaciones a las que aquí me refiero : El Galpón, el Teatro Circular de Montevideo (TCM) y Teatro Uno, desarrollen y empleen estrategias y procedimientos que les permitan, en los intersticios, desplegar su accionar teatral y político y en los momentos en que no es posible, replegarse para configurar nuevas formas de acción.

A su vez estos periodos o bloques históricos definen las etapas de la instauración del autoritarismo en Uruguay, y nos ayudan a comprender la vida social y cultural que se desarrolla en los márgenes e intersticios del consenso cultural que buscó imponer el régimen.

2. Pignataro, Jorge y Carbajal, Rosa (2010) Diccionario biográfico del teatro uruguayo. Ministerio de Educación y Cultura, Montevideo. Uruguay.

3. Enciclopedia online Itaú Cultural (2010), link : http://www.itaucultural.org.br/apli...

4. Archivo de Yamandu Marichal sistematizado por Roger Mirza: Programa de mano, Teatro Circular de Montevideo, Los Fusiles de la Patria Vieja, versión libre de 'Los Fusiles de la Madre Carrar' de Bertold Brecht, temporada 1971.

5. Archivo Institución teatral El Galpón, 'Entre Rejas', Montevideo, Miércoles 16 de agosto de 1972, no aparece medio de prensa

6. Archivo de la Dirección Nacional de Información e Inteligencia Carpeta : 'LETRA DE LA OBRA TEATRAL 'LA REJA' ; de Andrés Castillo'.-

7. Archivo de Yamandú Marichal sistematizado por Roger Mirza : programa de mano 'El Mono y su Sombra' de Yahro Sosa, Teatro Circular (sala dos), Octubre-Noviembre 1979, versión digital 


\section{RESÚMENES}

Este artículo es un análisis acerca de las formas de resistencia del teatro independiente, de las prácticas reales desarrolladas por algunas agrupaciones independientes antes y durante la última dictadura militar uruguaya, en pos de la supervivencia del campo cultural. En las luchas libradas por la dictadura por la 'dominación' del campo cultural, el teatro independiente jugó un papel fundamental para mantener espacios alternativos al 'consenso cultural' que el régimen buscó instalar y a través del cual buscó obtener el apoyo de la población. Este análisis distingue dos bloques históricos caracterizados por diferentes prácticas, repertorios y astucias de un conjunto de agrupaciones independientes. El primero de ellos, previo al golpe de Estado, abarca desde el año 1968 hasta el año 1973, punto en el cual la violencia política y la represión quedaron ya instaladas. El segundo bloque, que corresponde a la instauración del régimen dictatorial, se extiende entre los años 1973 y 1985.

L'article propose une analyse des formes de résistance du théâtre indépendant, des pratiques réelles développées par certains groupes autonomes avant et pendant la dernière dictature militaire uruguayenne, dans une perspective de survie du domaine culturel. Face à une dictature acharnée à dominer le champ culturel, le théâtre indépendant a joué un rôle clé pour maintenir des espaces alternatifs au « consensus culturel » que le régime cherchait à installer et par lequel il a tenté d'obtenir le soutien de la population. Cette analyse distingue deux périodes historiques caractérisées par les pratiques, les répertoires et les astuces de quelques groupes indépendants. La première, précédant le coup d'Etat, s'étend de 1968 à 1973, date à laquelle la violence politique et la répression étaient déjà à l'oeuvre. La seconde période, de 1973 à 1985, correspond à la mise en place du régime dictatorial.

\section{ÍNDICE}

Mots-clés: théâtre activiste, résistance, dictature, Uruguay

Palabras claves: teatro activista, resistencia, dictadura, Uruguay

\section{AUTOR}

\section{LUCIANA SCARAFFUNI}

lucianascaraffuni974[at]gmail.com 